\title{
Numerical Simulation of the Degree of Protection for K9 Artillery Position under Explosion Scenario Using METT+TC
}

\author{
Kukjoo Kim ${ }^{1,2}$ and Young-Jun Park $1,2, * \mathbb{D}$ \\ 1 Department of Civil Engineering and Environmental Sciences, Korea Military Academy, Seoul 01805, Korea; \\ kukjoo.kim@mnd.go.kr \\ 2 Nuclear.WMD Protection Research Center, Korea Military Academy, Seoul 01805, Korea \\ * Correspondence: parky@mnd.go.kr
}

Received: 28 October 2020; Accepted: 8 December 2020; Published: 9 December 2020

check for updates

Featured Application: In this study, a new methodology is presented to evaluate the degree of protection under blasting loading using finite element analysis.

\begin{abstract}
This study proposes a method to evaluate the protective performance of an existing K9 artillery position according to various explosion scenarios. Thus, a commercial software package AUTODYN was used to create a 3D model of the existing artillery position. Following the mission, enemy, terrain and weather, troops and support available, time available, and civil consideration (METT+TC) analysis, a total of three blast loading scenarios were selected. According to the results, the wall rotation angle of a near-miss explosion was within the standard of $2^{\circ}$; considering contact explosions, the rotation angles were also within $2^{\circ}$. This confirmed that the $\mathrm{K} 9$ artillery position under examination for protective performance was within the elastic design range. Considering the final evaluation and combining the results, the walls and slabs of the K9 artillery position were determined to be able to withstand the corresponding blast pressures and have no issues in protective performance. Meanwhile, due to the limitations of the actual blast tests for evaluating the protective performance of civilian protective structures and those of the ROK Armed Forces, these tests were replaced with numerical analysis-based evaluations. However, due to the lack of specified procedures for numerical analysis based on finite element analysis, there were several difficulties in practice. Therefore, this study aims to provide a basic procedure for evaluating the protective performance of protective structures in the future by presenting analytical and blast loading conditions which are necessary for evaluating protective performance.
\end{abstract}

Keywords: degree of protection; blast wave; explosion; finite element analysis

\section{Introduction}

Evaluating the degree of protection is an important factor in the design of military and civilian structures. Securing an adequate degree of protection in military facilities particularly plays a crucial role in achieving a national security strategy. One aspect of the protective structure evaluation is the structure's reliable degree of protection against blast loading. Empirical experiments are the most definite method of verifying the protective performance of structures subject to blast loading. However, repeating the experiment enough times to ensure reliable results is significantly expensive, and empirical experiments have numerous spatial, temporal, and economic constraints. Moreover, as the explosions for these empirical experiments can cause civilian damage due to noise and vibrations, they are conducted on a very limited basis. The installation of full-scale structures is another limitation that makes empirical experiments difficult to perform. Considering protective performance verification, 
protective facilities must be designed and verified to satisfy the Defense Military Facility Criteria (DMFC 4-70-00) depending on the facility under examination [1]. The required protective performance is specified in these criteria according to the protective facility type and purpose, and each structural member of the facility must be designed to satisfy these requirements.

After evaluating the blast pressure and penetration of the weapon, the protective structure is finally adopted based on the effects requiring the highest protective performance. Generally, the structure requires a deeper thickness than the penetration depth of the weapon; however, direct hits are rarely set as an enemy threat outside of special cases. Artillery projectiles and aircraft bombs are evaluated based on the scenario of a near-miss explosion, considering the weapon's accuracy. Penetration from direct hits causes severe local damage to certain elements of the structure, whereas blast waves cause overall damage of a relatively lesser severity to the structure. Therefore, careful examination of the overall protective structure's safety against blast waves is required. Thus, while local damage from the penetration can be verified by assessing the degree of protection of the materials and structural elements, for blast waves, the safety of the overall structure must be evaluated. As a result, evaluating the degree of protection against blast waves introduces challenges involving the assessment of the building's overall structural behavior [2-4]. The designer of the protective structure must first analyze the weapon effects, design the structural members, and then evaluate the overall structure's safety through blast resistance tests, though there are several constraints in reality. Many researchers have recently used finite element analysis as an alternative to blast loading verification using actual structures [5-10]. To verify protective performance through numerical analysis, the evaluator must first understand the loading effect of blasts on the structure. It is important to understand the structure's behavior when subject to blast loading. Because the numerical analysis of explosions concerns the structural behavior that manifests in a significantly short period of time, there are additional considerations such as inertial force, kinetic energy that differs from typical static numerical analyses [11,12].

Accordingly, to evaluate the protective performance of protective structures, this study aims to derive a method for evaluating the protective performance according to the blast loading scenario and provide a protective performance verification method through numerical analysis based on a case study. To identify the appropriate blast loading scenario, the weapon effects and dynamic factors pertaining to mission, enemy, terrain and weather, troops and support available, time available, and civil consideration (METT+TC) were considered. These dynamic factors are applied differently depending on the tactics and strategies of the military in each nation. Thus, through numerical analysis, this study observes the structural behavior according to the explosion on a K9 self-propelled artillery protective position installed in South Korea, which is the most used in the ROK Armed Forces, and compares and analyzes the evaluation results of the structure's degree of protection.

\section{Effect of Blast Loading on Protective Structures}

The protective structures must withstand dynamic loads created by explosions from high energy bombs and missiles, as well as loads from blast waves and debris collisions. These dynamic loads vary significantly with the characteristics of the weapon used to perform the hit. Generally, it is reasonable to set the protective performance required for protective facilities considering the mission, enemy, terrain and weather, troops and support available, time available, and civil considerations. Rather than direct hits, the structure should have a degree of protection against indirect weapon effects such as artillery projectiles $[13,14]$.

In a blast wave, as a significant amount of energy is suddenly released from an explosion, the pressure at the point of explosion rapidly increases and simultaneously spreads in all directions. When the shock front of the blast wave reaches a certain point at time $t_{a}$, as shown in Figure 1, the pressure at that point instantaneously rises from the ambient pressure to the maximum incident pressure. The pressure then decreases and returns to the ambient pressure at $t_{a}+t_{0}$ (positive phase), continues to decrease below the ambient pressure for the duration $t_{0-}^{-}$, and then returns to the ambient pressure at $t_{a}+t_{0}+t_{\overline{0}}$ (negative phase), after which it dissipates. The maximum pressure in the negative 
phase is referred to as the maximum suction pressure and is less than the positive pressure. In the pressure-time curve, the area of the positive and negative phases corresponds to the impulse $[15,16]$.

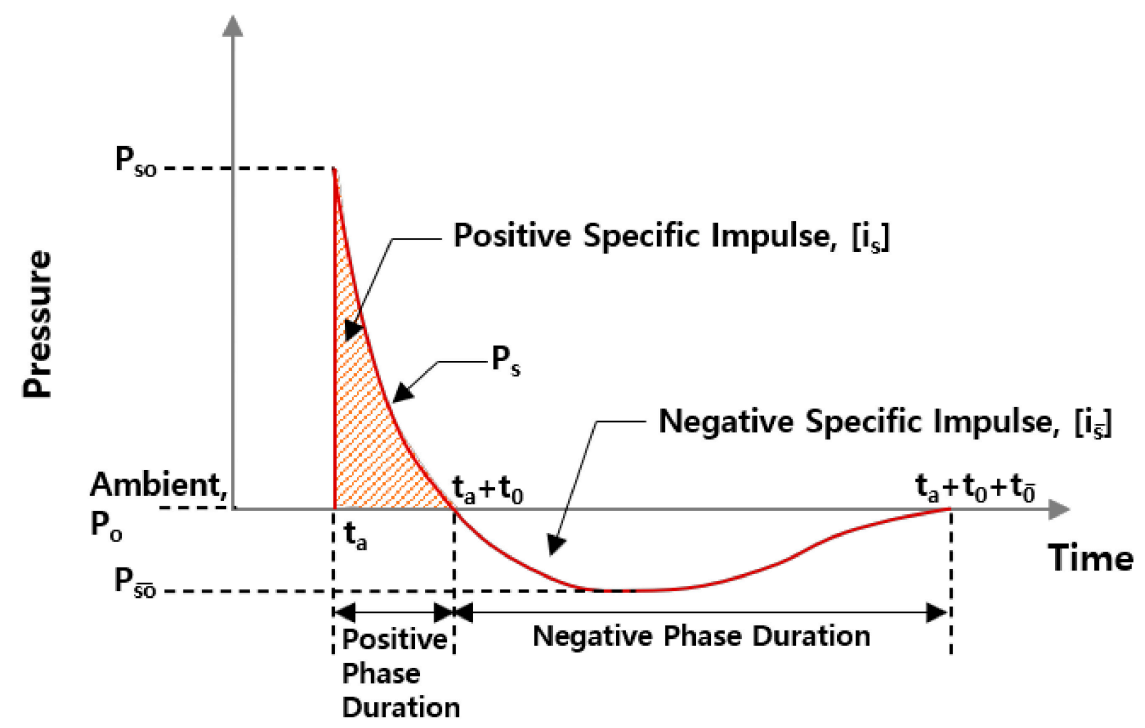

Figure 1. Idealized pressure-time curve of blast wave.

In terms of blast wave loading resulting from an explosion at a distance from a reinforced concrete structure, as shown in Figure 2, two cases can be considered: an explosion that occurs in air, or on a surface. When an explosion occurs in air, before the blast wave reaches the protective structure, a Mach front is formed by the interaction with reflected waves from the surface. The height of the Mach front increases with an increasing distance from the point of explosion, which is the same as the path of the triple point at which the incident pressure, reflected wave, and Mach front overlap. If the height of the protective structure is lower than the path of the triple point, then uniform blast wave loading is applied. Conversely, considering a surface explosion, the incident waves from the point of explosion merge with the reflected waves and propagate while forming a hemispherical single wave. In protective structure design, the blast wave front is assumed to have uniform pressure. Surface explosions are known to have a larger blast wave effect than explosions in the air $[17,18]$.

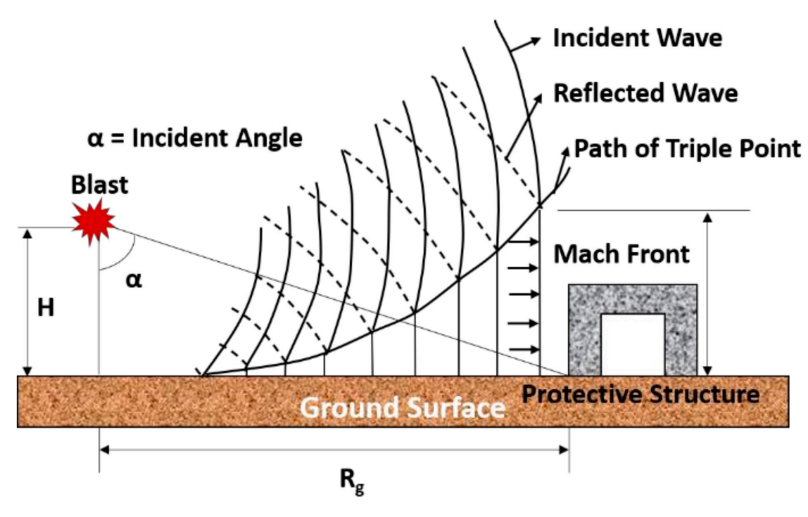

(a) Air bust blast environment

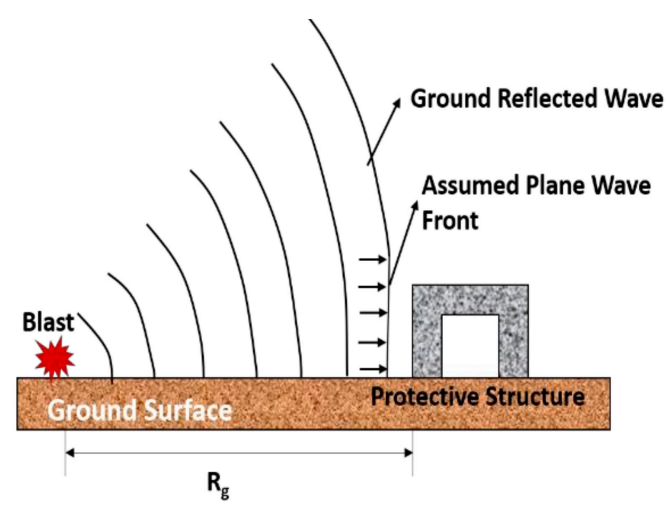

(b) Surface bust blast environment

Figure 2. Propagation of blast wave.

The protection levels used by the ROK Armed Forces comprises of a total of four stages; the displacement ductility and rotation angle thresholds proposed in the US Unified Facility Criteria (UFC) 3-340-02 are used for the protection levels [15]. The protection level, which is the protection goal of the protective structures including artillery positions, must comprehensively consider the degree of 
protection and enemy threats in terms of operations and information, as well as the facility's purpose of use. Once the protection level is determined, the structure must be operated within a certain range according to the protection level from blast loadings. Table 1 presents the allowable limit of the rotation angle according to each protection level applied to brittle materials such as concrete. The rotation angle refers to the maximum rotation angle at the point of the member when the blast loading is applied as shown in Figure 3 [19].

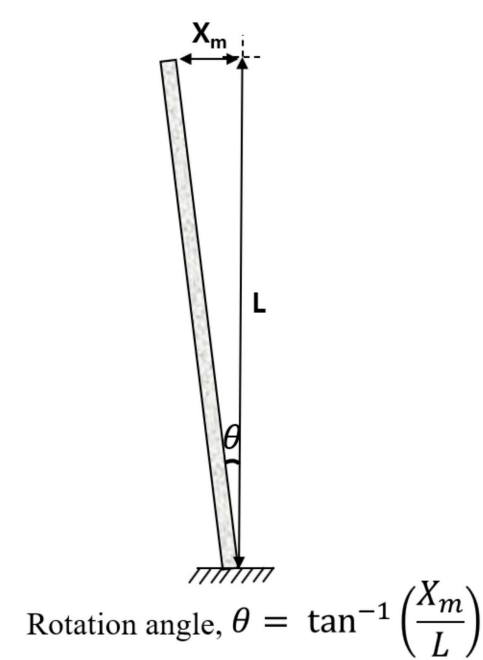

(a) One support condition

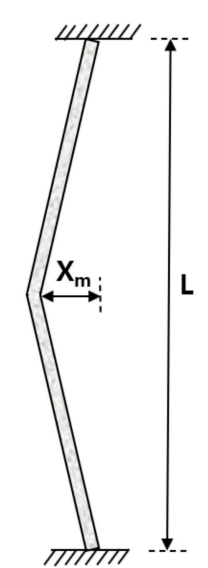

Rotation angle, $\theta=\tan ^{-1}\left(\frac{2 X_{m}}{L}\right)$

(b) Two support condition

Figure 3. Rotation angle at its supports.

Table 1. Design consideration of the protective facilities.

\begin{tabular}{cccc}
\hline $\begin{array}{c}\text { Protection } \\
\text { Level }\end{array}$ & $\begin{array}{c}\text { Construction } \\
\text { Method }\end{array}$ & Damage Aspect & $\begin{array}{c}\text { Damage } \\
\text { Aspect }\end{array}$ \\
\hline $\mathrm{A}$ & $\begin{array}{c}\text { Elastic design } \\
\text { (Working stress design) }\end{array}$ & Microcrack & $0 \sim 2^{\circ}$ \\
$\mathrm{B}$ & $\begin{array}{c}\text { Elasto-plastic design } \\
\text { Plastic design } \\
\text { (limit design) }\end{array}$ & $\begin{array}{c}\text { Protection for human lives and interior } \\
\text { possible (crack, crush) }\end{array}$ & $2 \sim 6^{\circ}$ \\
$\mathrm{C}$ & $\begin{array}{c}\text { Severe collapse (separation of } \\
\text { concrete form the reinforcement bar) }\end{array}$ & $6 \sim 12^{\circ}$ \\
\hline
\end{tabular}

Thus, it is the ratio of elastic deformation to maximum deformation. Though one may consider that both the rotational angle and deformation of the structural members according to explosive force must fall within these criteria to satisfy protective performance, in general, brittle materials such as concrete are based on rotational ductility, whereas ductile materials such as steel are based on displacement utility [1].

\section{Development of Methodology Using Finite Element Analysis}

\subsection{Review of FEA Packages}

To evaluate the blast resistance performance through numerical analysis, the evaluator must first understand the loading effect of blasts on the structure; it is also necessary to understand the structure's behavior when subject to blast loading [20-25]. Since the numerical analysis of explosions concerns structural behavior that manifests in a significantly short period of time, there are additional considerations that differ from typical static and dynamic numerical analyses [3,26-32].

There are mainly two types of computer software for analyzing the response of structures subject to blast loading: uncoupled analysis and coupled analysis. First, considering uncoupled analysis, the structure is assumed to be a rigid body and the blast pressure acting on the structure is obtained, 
after which the blast pressure is applied to the structure as a load and the structure's response is calculated. As the interactions between the structure and blast pressure are not considered and the structure is assumed to be a rigid body, this method tends to overestimate the blast loading. In coupled analysis, the ground or air, the medium that transfers the blast pressure is modeled and the blast pressure load and corresponding structural response is calculated through a fluid-structure interaction analysis. While this method can obtain more accurate structural responses, it has the disadvantage of being a lengthy analysis.

Commonly used commercial programs in this field include AUTODYN, DYNA3D, LS-DYNA, ABAQUS, BLASTX, CTH, FEFLO, FOIL, SHARC, ALE3D, and CONWEP, among which AUTODYN and LS-DYNA are the most used in Korea. LS-DYNA is based on structural element (solid) analysis and has the advantages of solid collision analysis at low/medium speeds, large deformation/large displacement analysis, nonlinear analysis, and drop test analysis [33]. AUTODYN, a representative analysis program capable of coupling fluids and solids, has the advantages of large deformation/large displacement analysis and nonlinear analysis, in addition to the analysis of shockwave transmission according to fluid characteristics, structural behavior according to solid/fluid coupling, and high-speed shock. Hence, LS-DYNA can be used for uncoupled analysis, whereas AUTODYN can perform coupled analysis. The results of coupled analysis for structural responses to blast loading are typically more accurate. Therefore, this study will use the AUTODYN software package to model an actual K9 artillery position and evaluate its degree of protection.

\subsection{Finite Element Modelling}

The AUTODYN software package was used to evaluate the degree of protection of the K9 self-propelled artillery position. There are several material options provided for the modeling of the structure elements in AUTODYN. In this study, the RHT (Riedel-Hiermaier-Thoma) dynamic damage concrete model in which the strain hardening and the third invariant dependence were considered is applied to present the behavior of the concrete during blasting loading. The RHT model is expressed by three strength surfaces defined as failure surface, elastic limit surface, and residual surface [34,35]. The elastic strength surface can reflect material strain hardening behavior. The residual strength surface can express the strength of completely crushed concrete under ultimate blasting loading. In addition, the concrete in the constitutive relation of FE model is considered as a quasi-brittle material with different behavior in compression and tension under blasting loading. A typical stress-strain curve for concrete is shown in Figure 4.

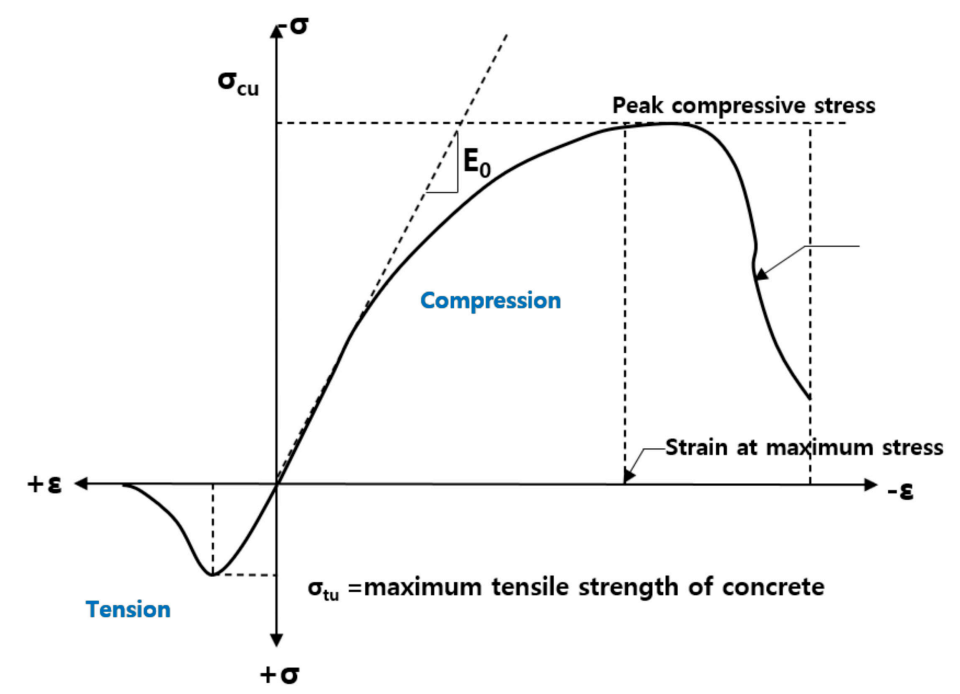

Figure 4. Typical uniaxial compression and tensile stress-strain curve for concrete. 
For streel reinforcement in a 3D stress space, the Johnson and Cook constitutive model was used to describe the steel behavior inside the concrete subjected to large strains and high strains with high temperature [36]. A bilinear elastoplastic stress-strain curve for steel is shown in Figure 5.

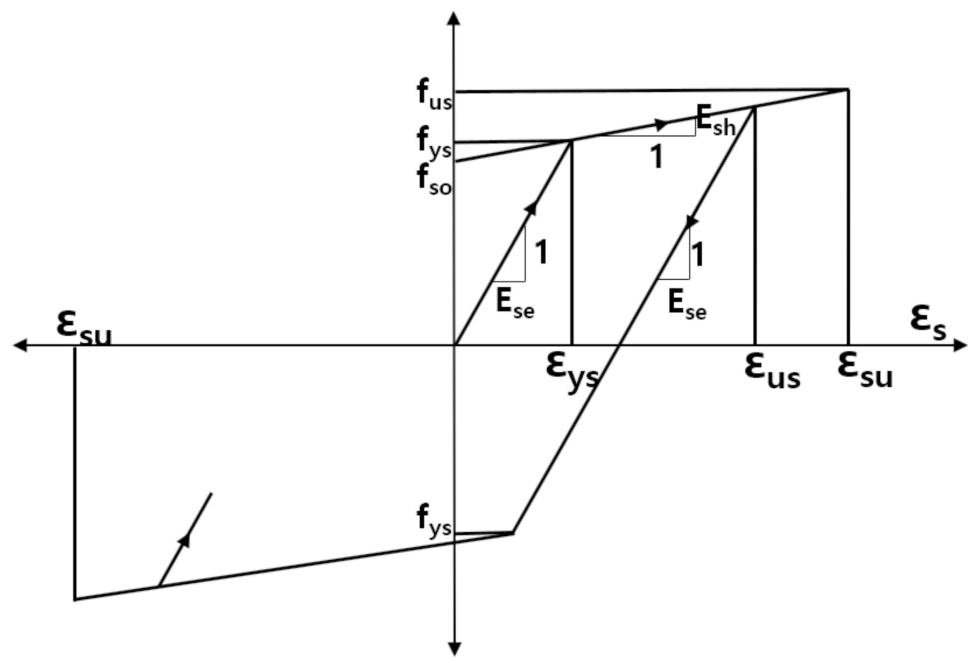

Figure 5. Stress-strain curve for steel reinforcement.

Air was modeled as an ideal gas with a density of $1.225 \mathrm{~kg} / \mathrm{m}^{3}$, an initial internal energy of kJ/kg and adiabatic exponent (gamma) of 1.4. Table 2 presents the structural specifications and material properties used in FE model.

Table 2. Material properties used in FE model.

\begin{tabular}{|c|c|c|}
\hline Category & \multicolumn{2}{|c|}{ Parameter } \\
\hline \multirow{5}{*}{ Concrete } & Compressive Strength & $30 \mathrm{MPa}$ \\
\hline & Elastic Modulus & $28,000 \mathrm{MPa}$ \\
\hline & Poisson's ratio & 0.19 \\
\hline & Bulk Modulus & $35.27 \mathrm{GPa}$ \\
\hline & Density & $2.75 \mathrm{~g} / \mathrm{cm}^{3}$ \\
\hline \multirow{7}{*}{ Reinforcement } & Yield Strength & $400 \mathrm{MPa}$ \\
\hline & Elastic Modulus & $232,800 \mathrm{MPa}$ \\
\hline & Poisson's ratio & 0.28 \\
\hline & Density & $7.83 \mathrm{~g} / \mathrm{cm}^{3}$ \\
\hline & Bulk modulus & $1.59 \times 10^{8} \mathrm{kPa}$ \\
\hline & Shear modulus & $8.18 \times 10^{7} \mathrm{kPa}$ \\
\hline & Diameter & HD13, HD16, HD19 \\
\hline \multirow{4}{*}{ Structure size } & Width & $37.30 \mathrm{~m}$ \\
\hline & Length & $20.35 \mathrm{~m}$ \\
\hline & Height & $6.94 \mathrm{~m}$ \\
\hline & Wall Thickness & $600 \mathrm{~mm}, 500 \mathrm{~mm}, 430 \mathrm{~mm}$ \\
\hline \multirow{3}{*}{ Air } & Density & $1.225 \mathrm{~kg} / \mathrm{m}^{3}$ \\
\hline & Gamma & 1.40 \\
\hline & Initial Internal Energy & $206,800 \mathrm{~kJ} / \mathrm{kg}$ \\
\hline \multirow{3}{*}{ TNT } & Density & 1.630 \\
\hline & Detonation velocity & $6.93 \times 10^{3} \mathrm{~m} / \mathrm{s}$ \\
\hline & Energy/unit volume & $6.00 \times 10^{6} \mathrm{~kJ} / \mathrm{m}^{3}$ \\
\hline
\end{tabular}

To model in AUTODYN, ANSYS Space-Claim was used to design the geometry of the model to analyze the air layers, walls, and slabs, as shown in Figure 6. The basic condition of the structure was set to fixed support, the joint condition of the heterogeneous materials of the concrete and reinforcing 
steel was assumed to be sufficiently integrated, and the corresponding effect on flexure was examined rather than the effect on shearing. Considering the air boundary conditions for the analysis, the five surfaces excluding the bottom surface were set to flow out, and the bottom surface touching the ground was set to reflection with a coefficient of 1.8 [37]. This was to reflect the consequent energy losses to displace the ground, i.e., for cratering [1,37]. The blast pressure was measured at a total of 47 sensor locations to evaluate the structural response of the protective structure. Figure 7 presents the sensor locations. Gauges were placed at $500 \mathrm{~mm}$ intervals on the walls and slabs of the K9 artillery position; the displacement, velocity, and acceleration in the structure were measured; and the blast pressure was measured at $500 \mathrm{~mm}$ intervals in the air layer.

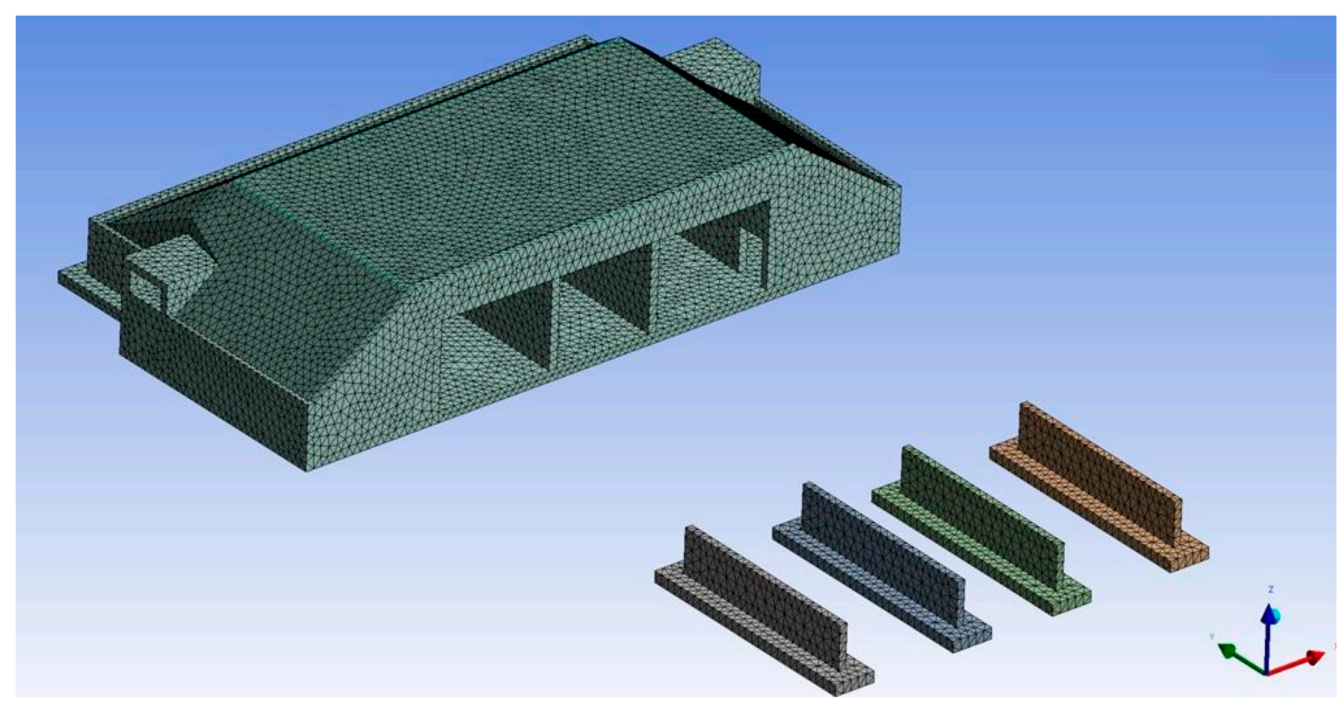

Figure 6. Finite element model developed.

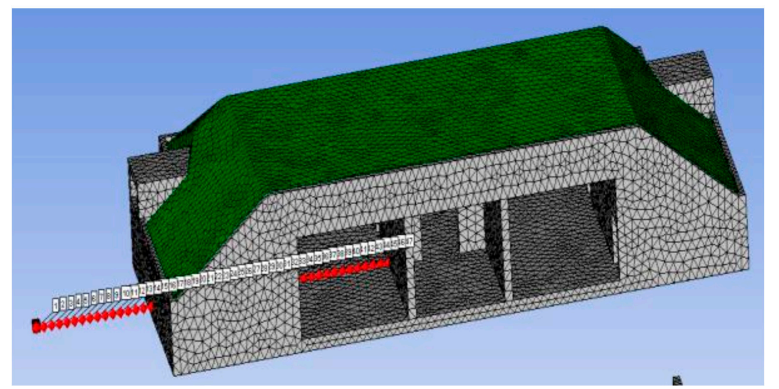

(a) Blast pressure gauge

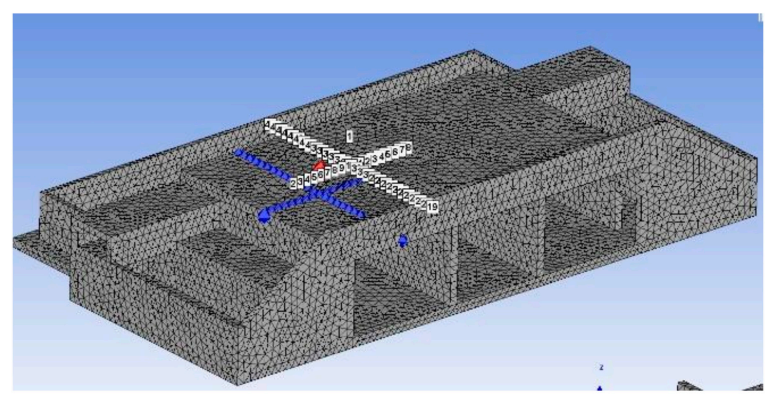

(c) Roof displacement gauge

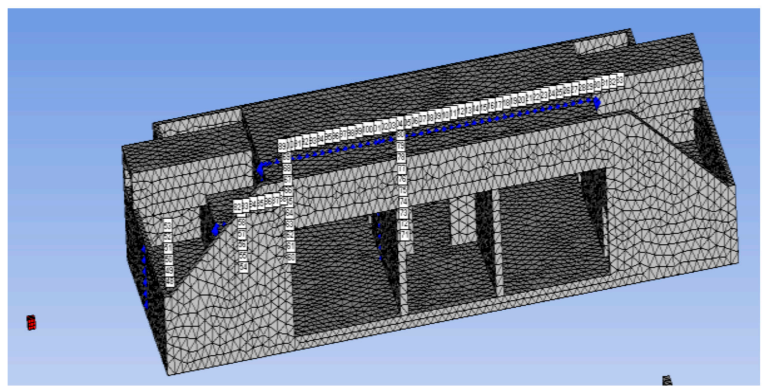

(b) Structural displacement gauge

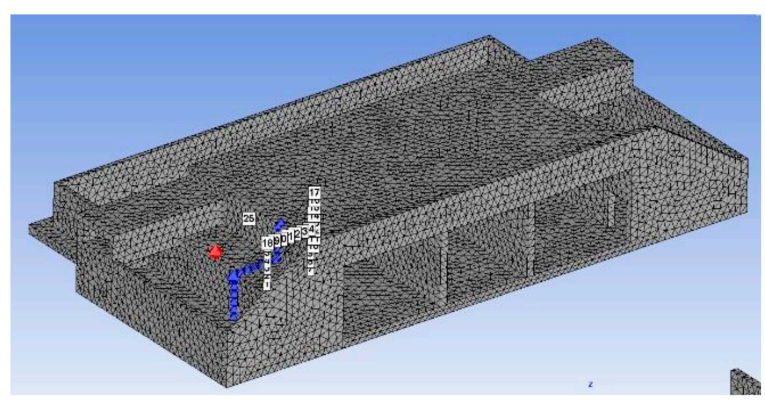

(d) Wall displacement gauge

Figure 7. Gauge locations to measure blast pressure and structural displacement. 


\subsection{Blasting Loading Conditions Using Case the Study}

The degree of protection of the K9 artillery position was evaluated under three blast loading cases as shown in Figure 8. Unfortunately, the detailed information about the explosion scenario is restricted due to military secrets, since military facilities that are actually in operation are used in this study. Specific information about the explosion scenario can be used to back-calculate the capabilities of the protection facility used in this study.

- Case 1: Protection class 00 load case; separation distance of $0.0 \mathrm{~m}, 000 \mathrm{~kg}$ bomb with $00 \%$ explosive content (restriction on disclosure due to military secrets)

- Case 2: $00 \mathrm{~kg}$ explosive; contact explosion with roof cover

- Case 3: $00 \mathrm{~kg}$ explosive; contact explosion with wall cover

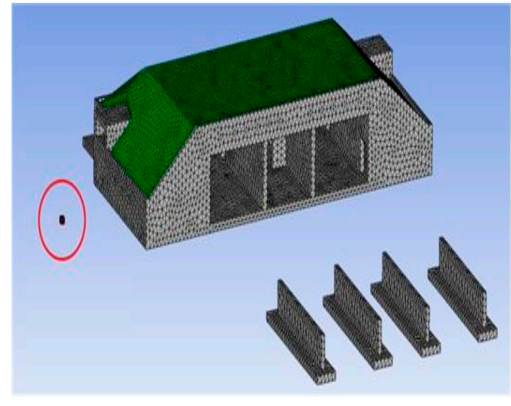

(a) Case 1

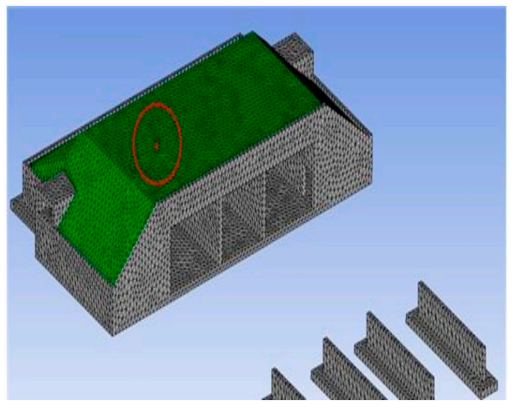

(b) Case 2

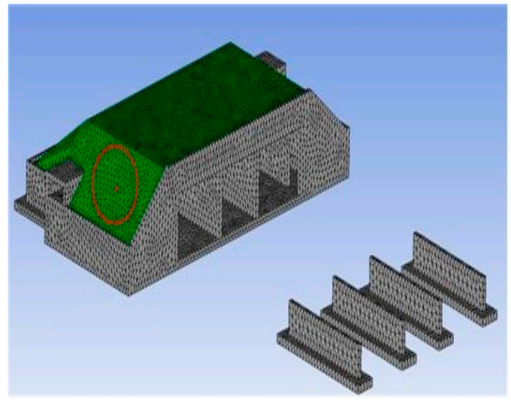

(c) Case 3

Figure 8. Basting load cases.

\section{Results of FEA}

Figures 9 and 10 present the blast pressure distribution, displacement, velocity, and acceleration values of the $\mathrm{K} 9$ artillery position for Case 1 . The blast pressure was expressed in 3-ms intervals from 5 $\mathrm{ms}$ to $20 \mathrm{~ms}$. Figure 8 presents the positive and negative pressures of the blast pressure; in Case 1, the maximum blast pressure was delivered to an external wall (wall No. 6) close to the explosion location at approximately $5.5 \mathrm{~ms}$. The maximum blast pressure occurred at the distance closest to the blast wave point and sharply decreased with distance. Figure 9 is a graph of the displacement, velocity, and acceleration measured at wall No. 6 . The deformation caused by the blast pressure was examined in terms of positive and negative pressure. According to the simulation results of Case 1 , a maximum blast pressure of $452.02 \mathrm{kPa}$ was measured in front of No. 6 at ground height, and the maximum displacement of wall No. 6 was measured at $0.129 \mathrm{~mm}$.

Figures 11 and 12 are graphs of the displacement, velocity, and acceleration measured at slab under explosion (slab No. 1) for Case 2. The deformation caused by the blast pressure was examined in terms of positive and negative pressure, and the blast pressure measured at the center of the explosion in Case 2 was 49,962 $\mathrm{kPa}$. The maximum displacement of slab No. 1 in Case 2 was measured to be $1.094 \mathrm{~mm}$.

Figures 13 and 14 present the simulation results of the Case 3 explosion scenario. In Case 3, the blast pressure measured at the center of the explosion was $49,962 \mathrm{kPa}$, and the maximum displacements of wall No. 4 (the wall closest to the slab where the explosion occurred), wall No. 1 (farthest wall of the explosion), and slab under explosion (slab No. 2) were measured to be $0.089 \mathrm{~mm}, 0.114 \mathrm{~mm}$, and $0.136 \mathrm{~mm}$, respectively. Table 3 , a summary of the simulation results, presents the calculated values of the maximum positive pressure and maximum displacement of each wall and slab. 
Table 3. Summary of FE Analysis results.

\begin{tabular}{ccccc}
\hline & Category & Time (ms) & Value & $\begin{array}{c}\text { Maximum } \\
\text { Rotation Angle }\end{array}$ \\
\hline \multirow{2}{*}{ Case 1 } & Positive Pressure & 5.5 & $452.02 \mathrm{kPa}$ & - \\
& Displacement Negative Pressure (wall No. 6) & 112.5 & $0.129 \mathrm{~mm}$ & $0.005^{\circ}$ \\
& Displacement Positive Pressure (wall No. 6) & 100.5 & $0.083 \mathrm{~mm}$ & $0.004^{\circ}$ \\
\hline \multirow{2}{*}{ Case 2 } & Positive Pressure & 0 & $49,928 \mathrm{kPa}$ & - \\
& Displacement Positive Pressure (slab No. 1) & 20.2 & $1.094 \mathrm{~mm}$ & $0.016^{\circ}$ \\
\hline \multirow{2}{*}{ Case 3 } & Positive Pressure & 0 & $49,962 \mathrm{kPa}$ & - \\
& Displacement Negative Pressure (wall No. 4) & 21.4 & $0.089 \mathrm{~mm}$ & $0.004^{\circ}$ \\
& Displacement Negative Pressure (wall No. 1) & 21.0 & $0.114 \mathrm{~mm}$ & $0.002^{\circ}$ \\
& Displacement Positive Pressure (slab No. 2) & 59.0 & $0.136 \mathrm{~mm}$ & $0.005^{\circ}$ \\
\hline
\end{tabular}

As shown in Table 3, the rotation angle at the maximum deformation of wall No. 6 in Case 1 was calculated at $0.005^{\circ}$ (wall height $=2.9 \mathrm{~m}$, maximum displacement $=0.129 \mathrm{~mm}$ ), and the rotation angle at the maximum deformation of slab No. 1 in Case 2 at $0.016^{\circ}$ (short side length $=8.0 \mathrm{~m}$, maximum displacement $=1.094 \mathrm{~mm}$ ). In addition, the following rotation angles were calculated for Case 3 : $0.004^{\circ}$ for wall No. 4 (wall height $=2.9 \mathrm{~m}$, maximum displacement $=0.089 \mathrm{~mm}$ ), $0.002^{\circ}$ for wall No. 1 (wall height $=5.23 \mathrm{~m}$, maximum displacement $=0.114 \mathrm{~mm}$ ), and $0.005^{\circ}$ for slab No. 2 (short side length $=3.1 \mathrm{~m}$, maximum displacement $=0.136 \mathrm{~mm}$ ). The rotation angle of wall No. 6 in Case 1 , which applies a separation distance of $0.0 \mathrm{~m}$, was confirmed to be within $2^{\circ}$ of the rotation angle recommended by the standard (see Table 1). The rotation angles resulting from the contact explosion of the $00 \mathrm{~kg}$ explosive in Cases 2 and 3 were also within $2^{\circ}$. Hence, the $\mathrm{K} 9$ artillery position, the target structure of the protective performance verification, is considered to be within the elastic design range. Considering the final evaluation, upon combining the results, the structural members (walls and slabs) of the $\mathrm{K} 9$ artillery position, i.e., wall No. 6 (Thickness $=300 \mathrm{~mm}$ ), wall No. 1 (Thickness $=500 \mathrm{~mm}$ ), wall No. 4 (Thickness $=430 \mathrm{~mm}$ ), slab No. 1 (Thickness $=430 \mathrm{~mm})$, and slab No. $2($ THK. $=430 \mathrm{~mm}$ ), were determined to be able to withstand the corresponding blast pressures and have no issues in the protective performance under the protection level 00 and $00 \mathrm{~kg}$ contact explosions to the cover surface.

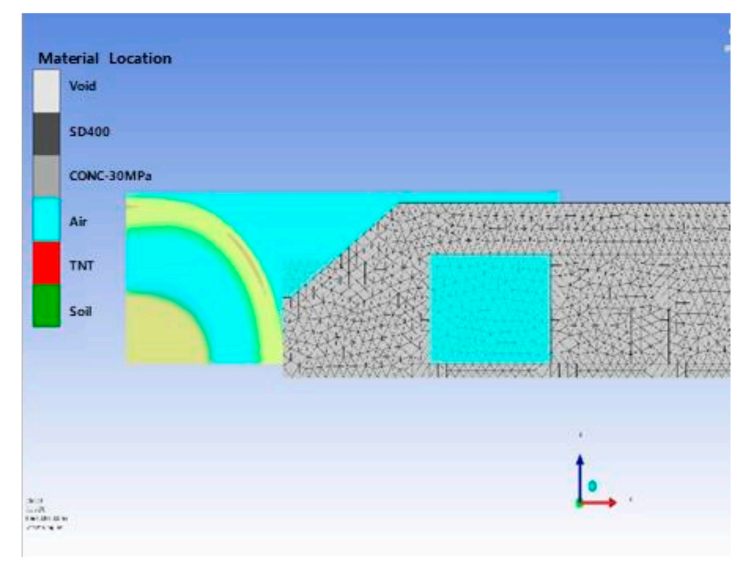

(a) $5 \mathrm{~ms}$

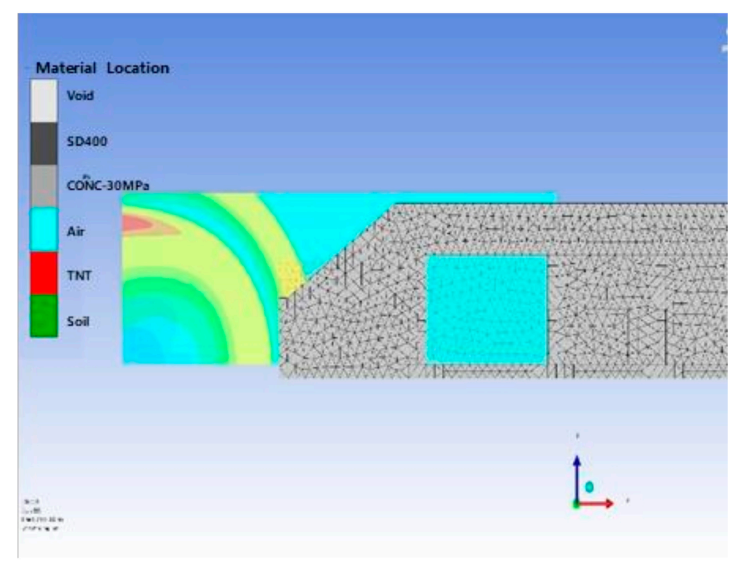

(b) $8 \mathrm{~ms}$

Figure 9. Cont. 


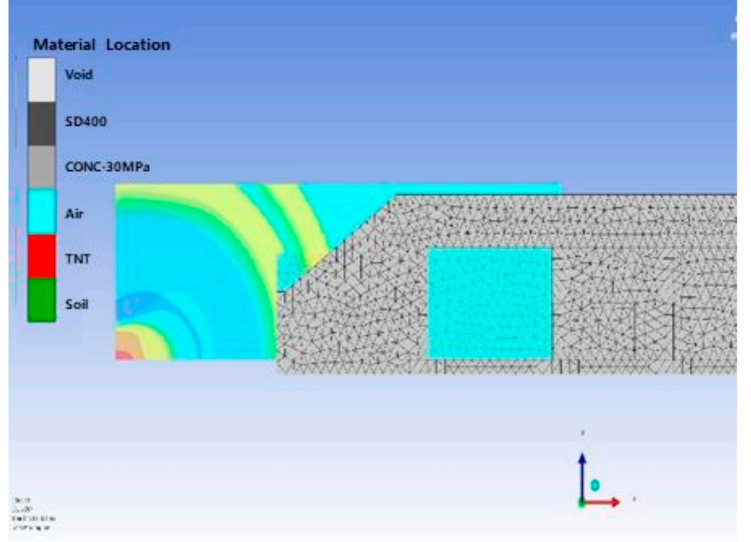

(c) $11 \mathrm{~ms}$

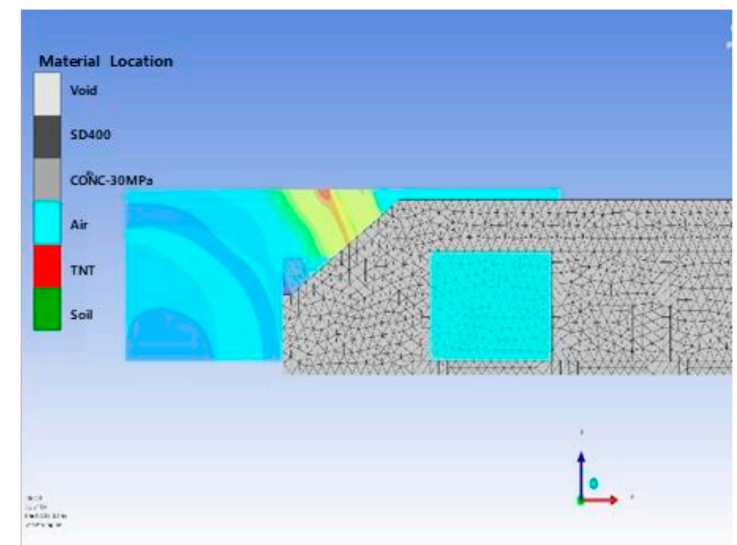

(e) $17 \mathrm{~ms}$

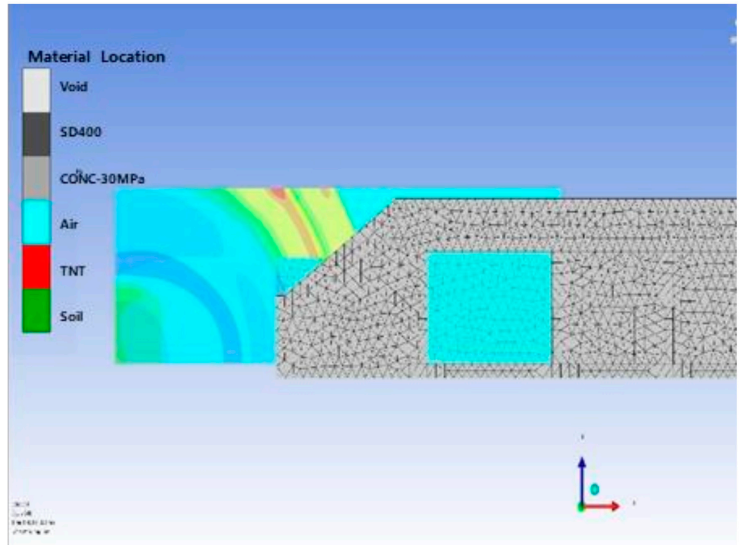

(d) $14 \mathrm{~ms}$

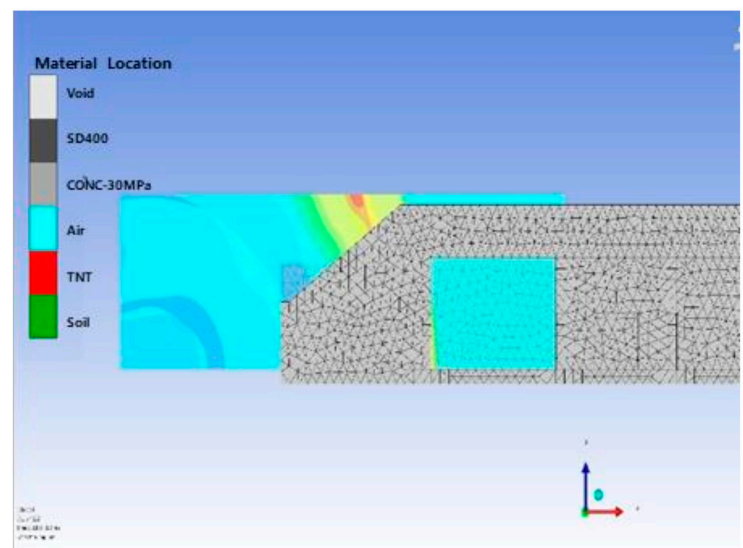

(f) $20 \mathrm{~ms}$

Figure 9. Blast load for Case 1.

Gauge History (Ident 0 - admodel )

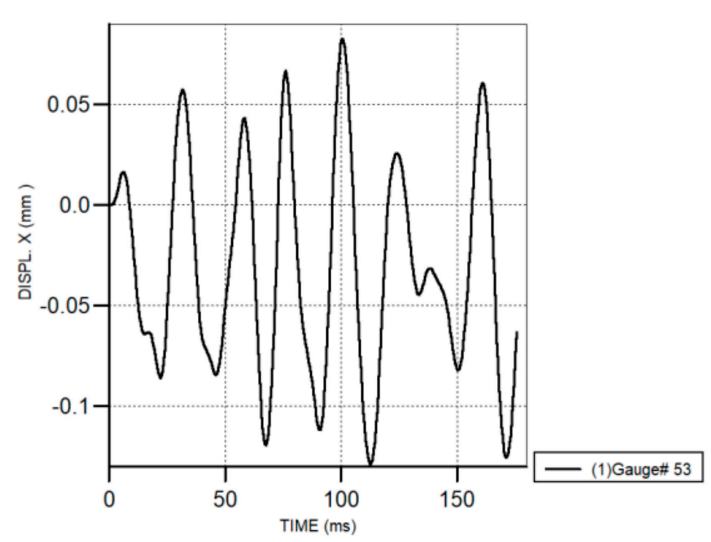

(a) Displacement $-X$ (Gauge\#53)
Gauge History ( Ident 0 - admodel )

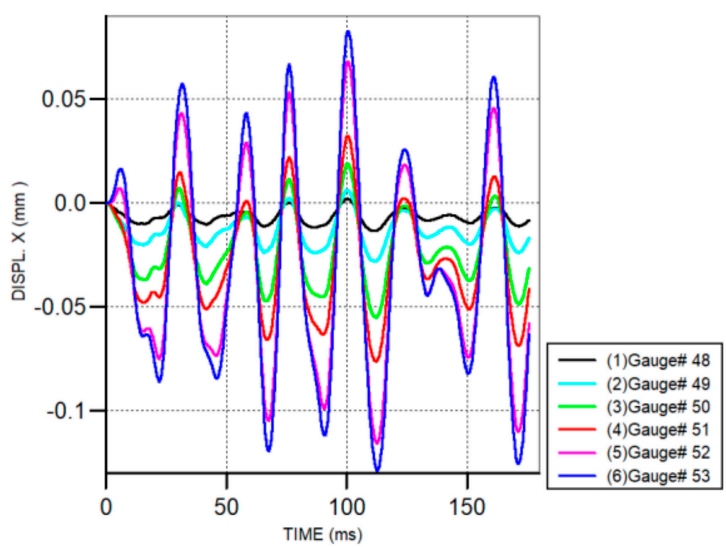

(b) Displacement $-X$ (entire wall No. 6)

Figure 10. Cont. 
Gauge History ( Ident 0 - admodel )

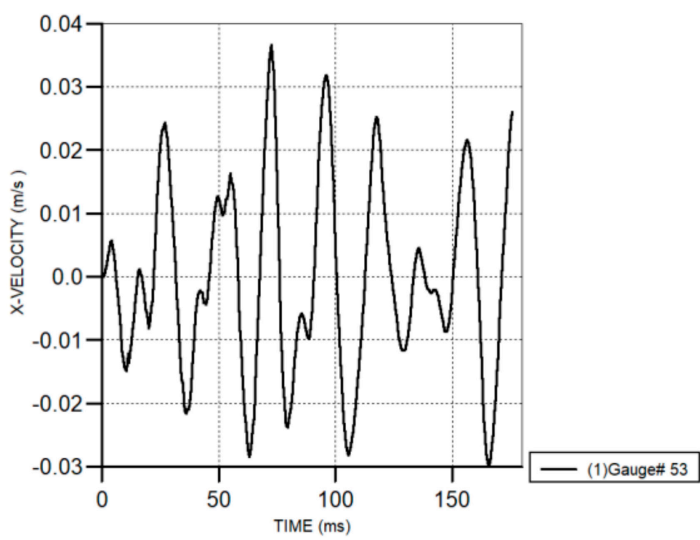

(c) Velocity -X (Gauge\#53)

Gauge History ( Ident 0 - admodel )

*10

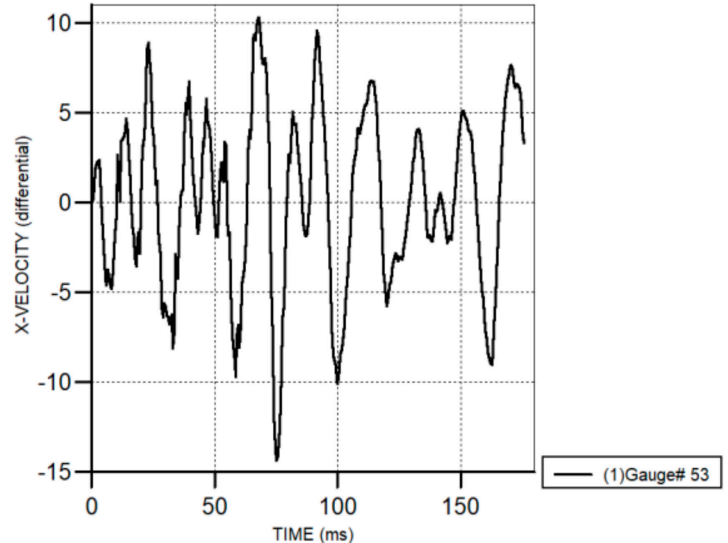

(e) Acceleration $-\mathrm{X}$ (Gauge\#53)
Gauge History ( Ident 0 - admodel )

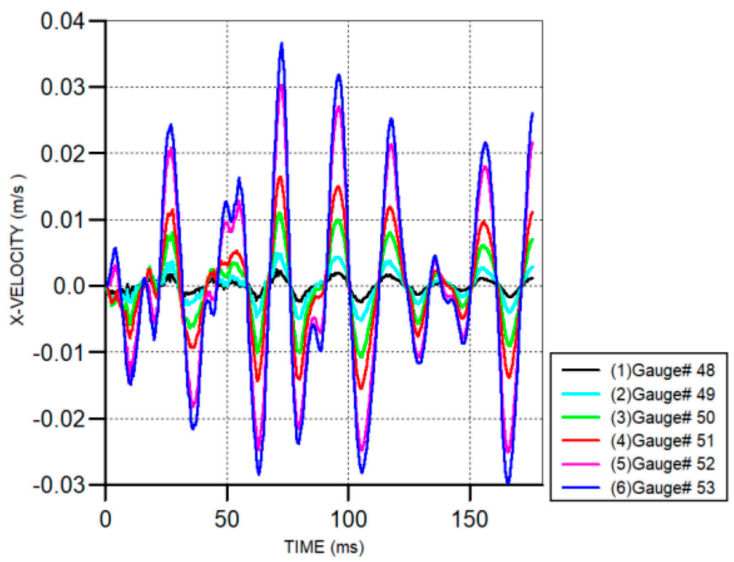

(d) Velocity -X (entire wall No. 6)

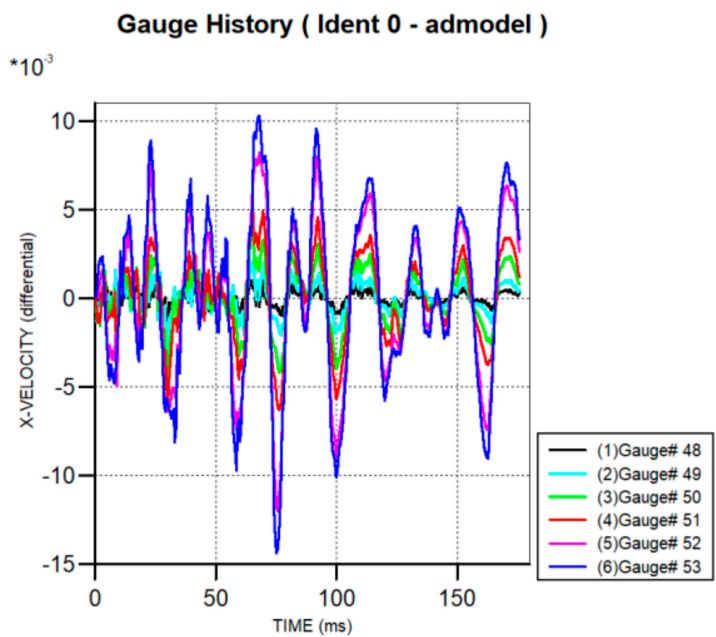

(f) Acceleration -X (entire wall No. 6)

Figure 10. Displacement, velocity, and acceleration at certain sensors for Case 1.

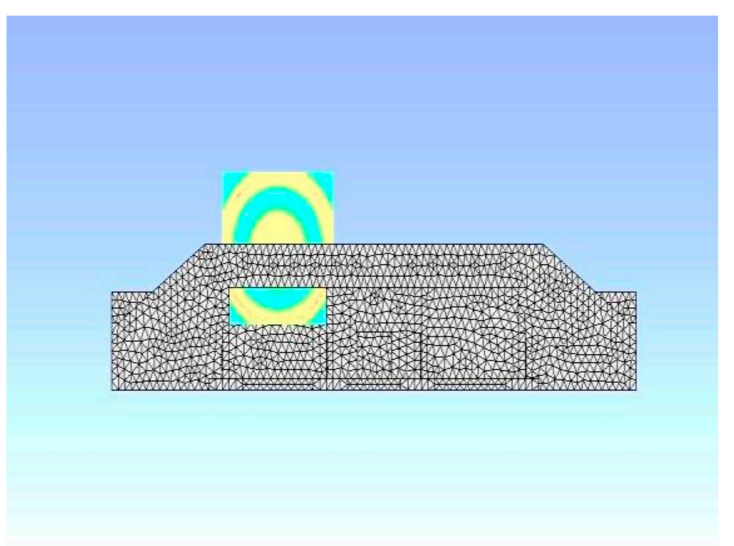

(a) $5 \mathrm{~ms}$

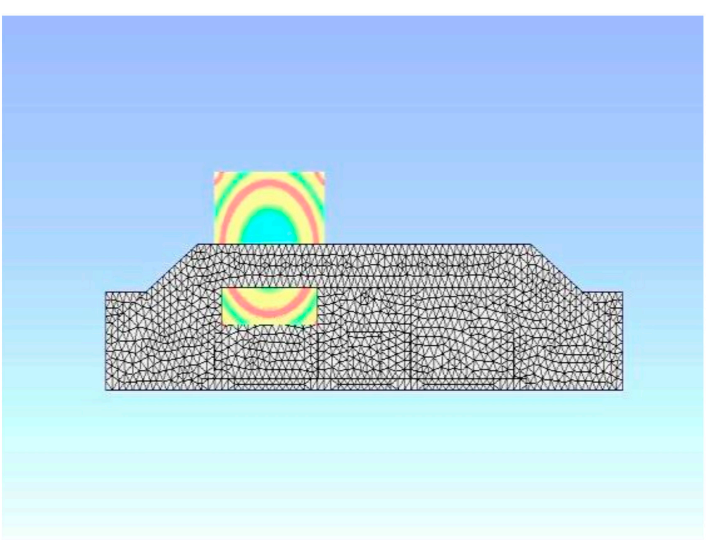

(b) $8 \mathrm{~ms}$

Figure 11. Cont. 


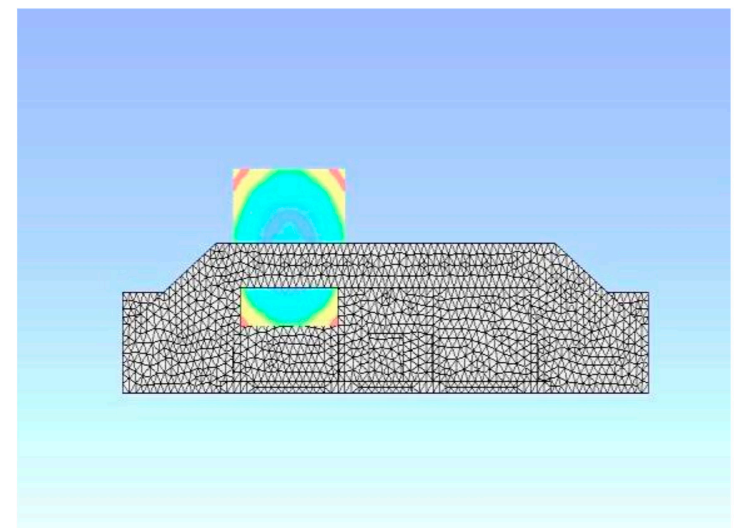

(c) $11 \mathrm{~ms}$

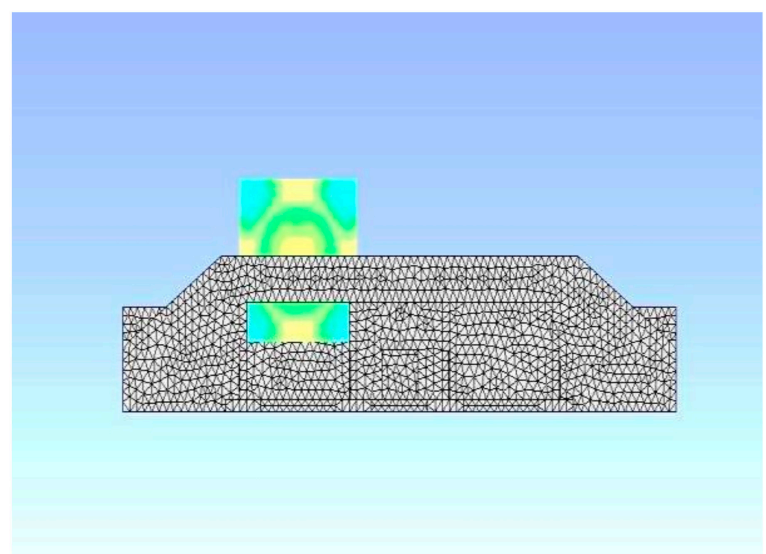

(e) $17 \mathrm{~ms}$

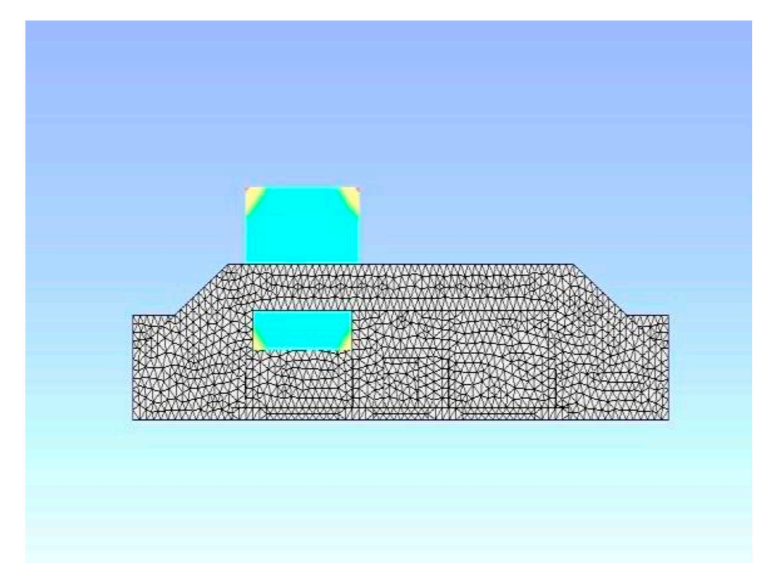

(d) $14 \mathrm{~ms}$

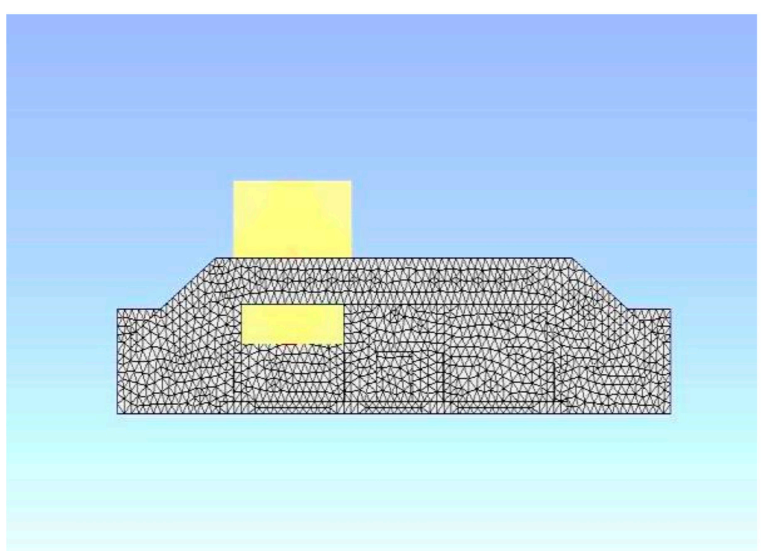

(f) $20 \mathrm{~ms}$

Figure 11. Blast load for Case 2.

Gauge History ( Ident 0 - admodel )

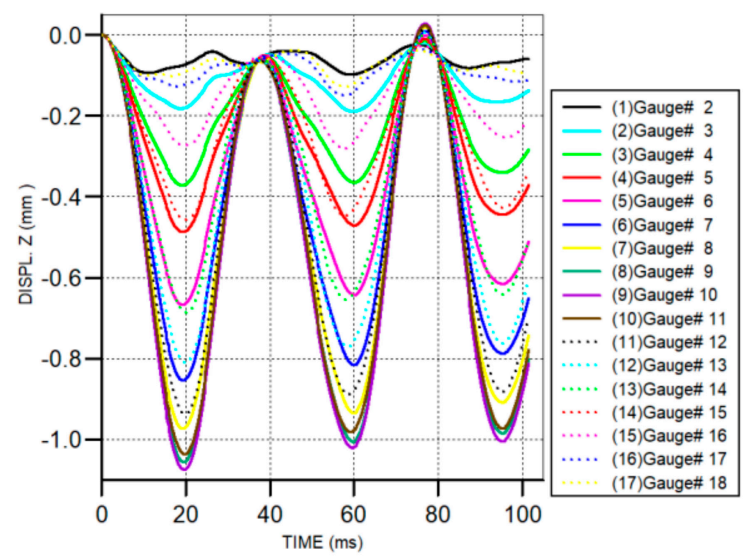

(a) Displacement-Z (short surface)

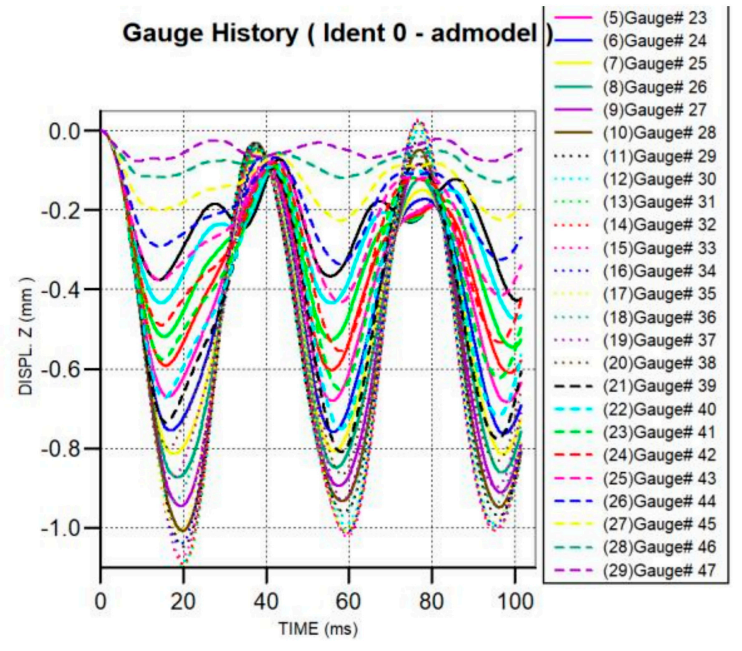

(b) Displacement - Z (long surface)

Figure 12. Cont. 
Gauge History (Ident 0 - admodel)

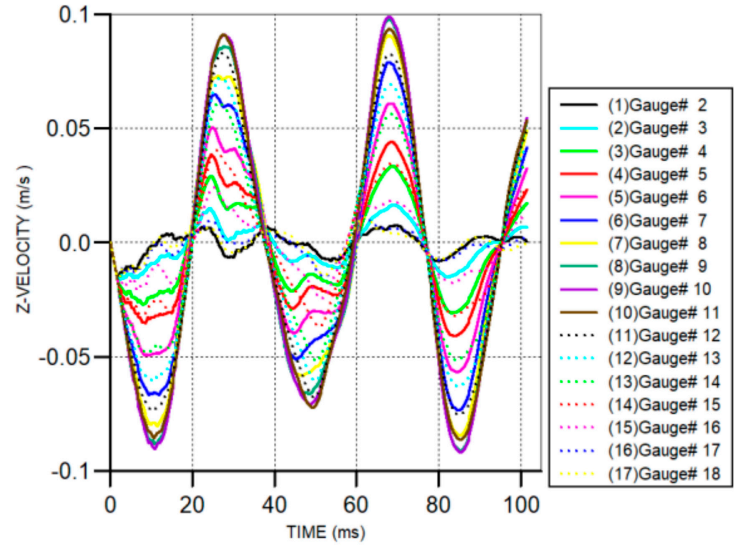

(c) Velocity $-Z$ (short surface)

Gauge History (Ident 0 - admodel )

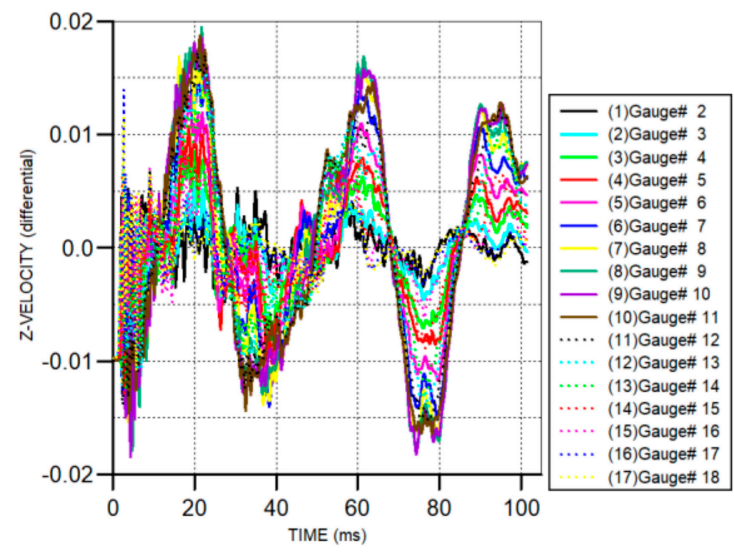

(e) Acceleration $-Z$ (short surface)

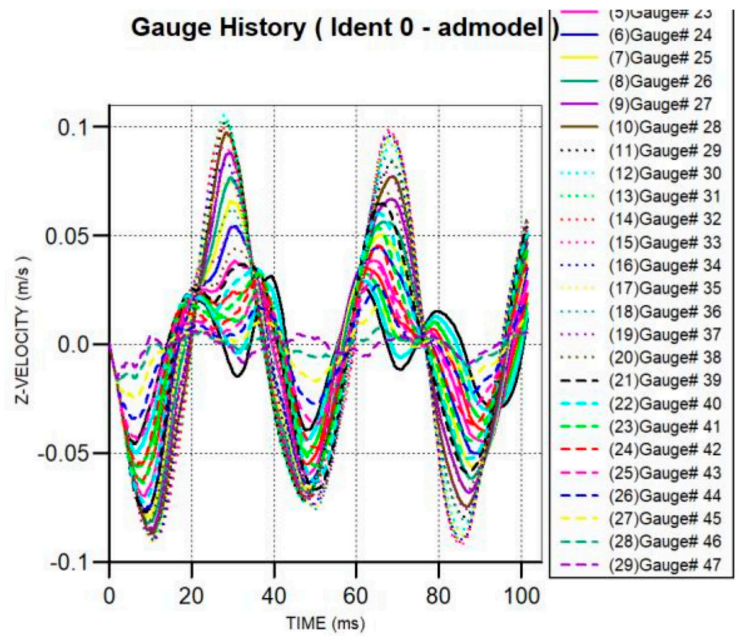

(d) Velocity $-Z$ (long surface)

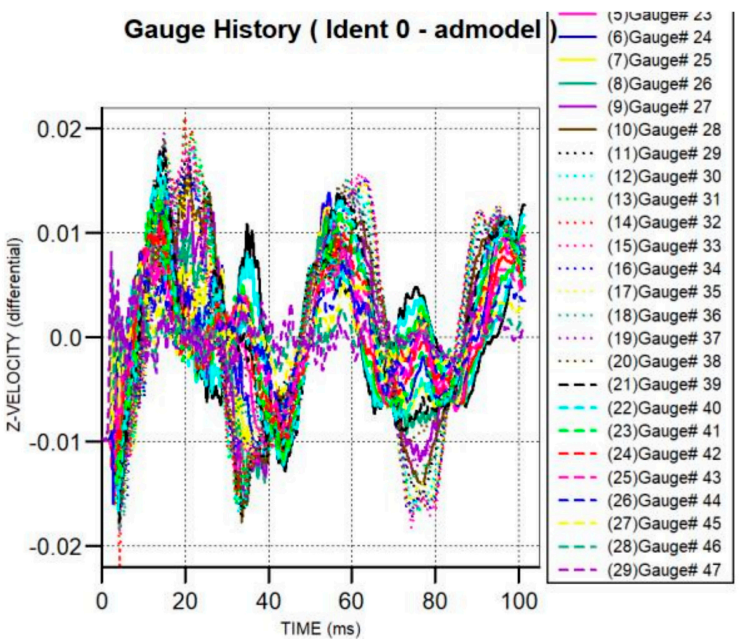

(f) Acceleration $-Z$ (long surface)

Figure 12. Displacement, velocity, and acceleration at certain sensors for Case 2.

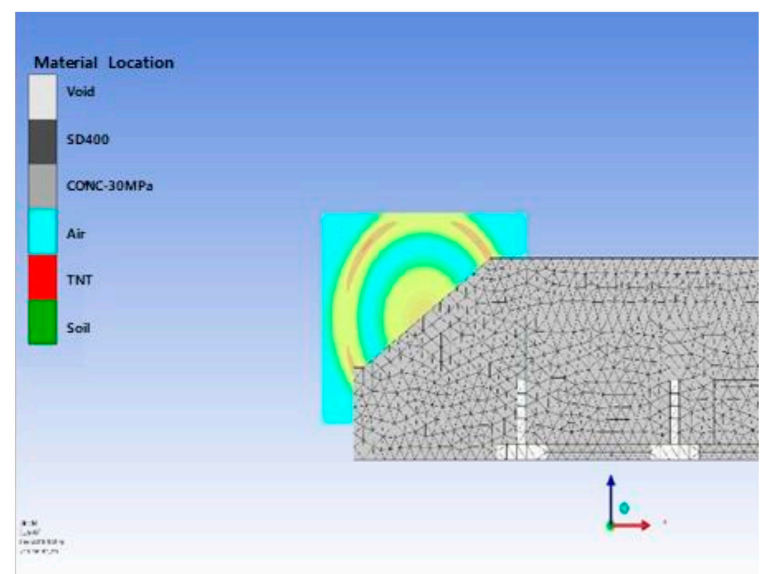

(a) $5 \mathrm{~ms}$

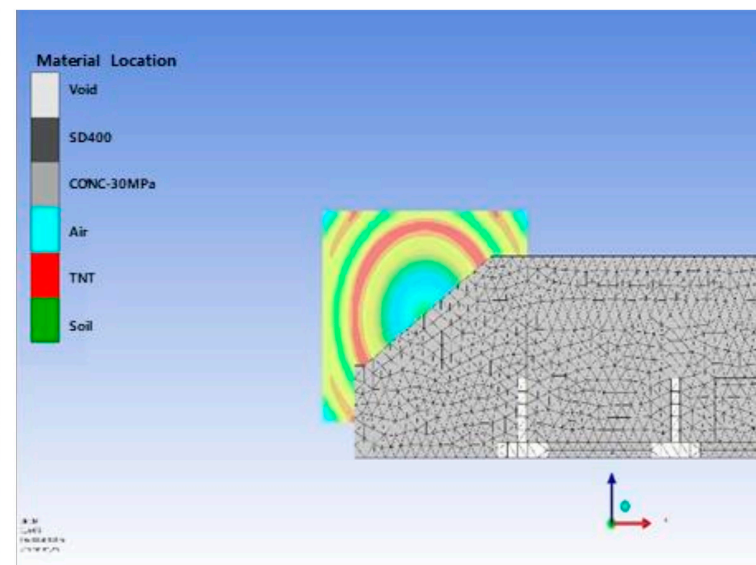

(b) $8 \mathrm{~ms}$

Figure 13. Cont. 


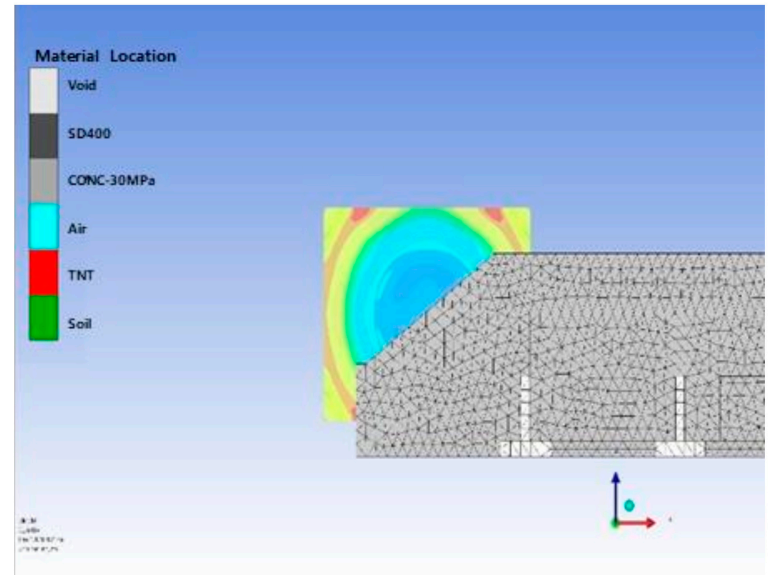

(c) $11 \mathrm{~ms}$

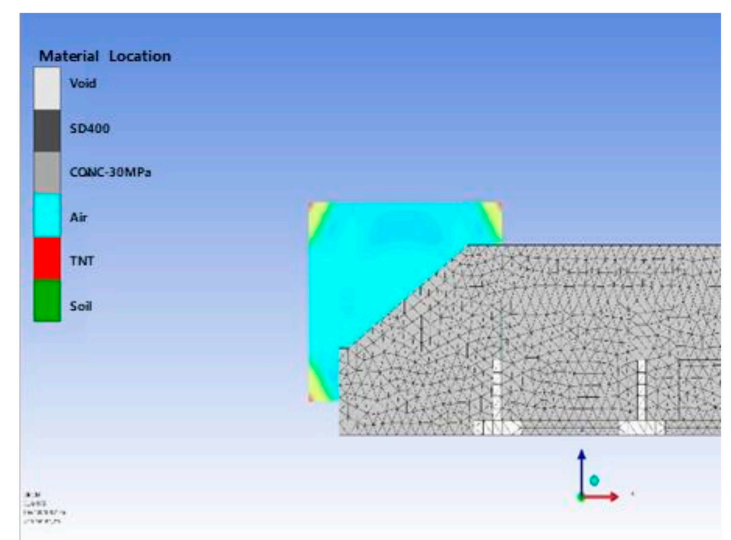

(e) $17 \mathrm{~ms}$

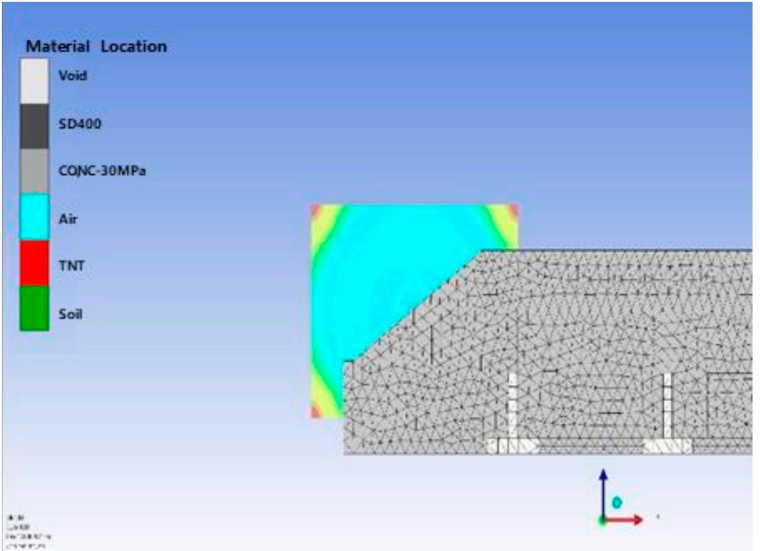

(d) $14 \mathrm{~ms}$

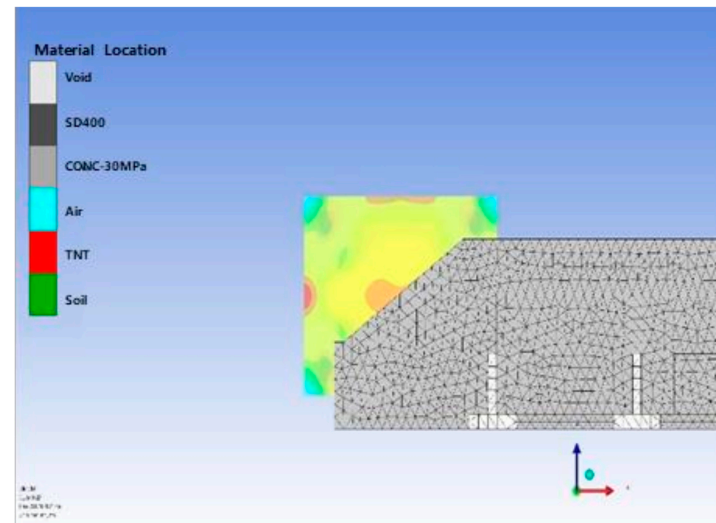

(f) $20 \mathrm{~ms}$

Figure 13. Blast load for Case 3.

Gauge History ( Ident 0 - admodel )

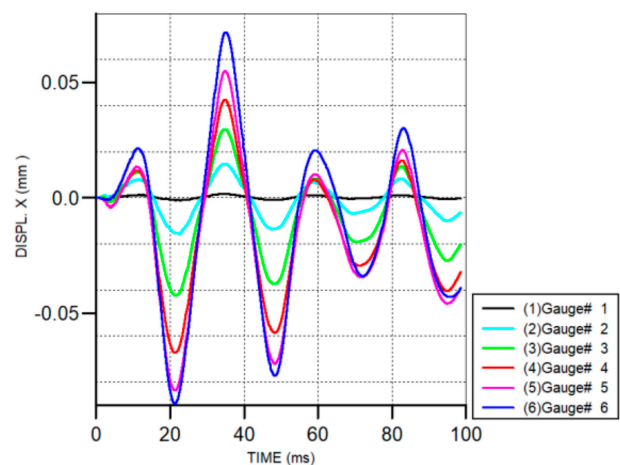

(a) Displacement-X (entire wall No. 4)
Gauge History (Ident 0 - admodel )

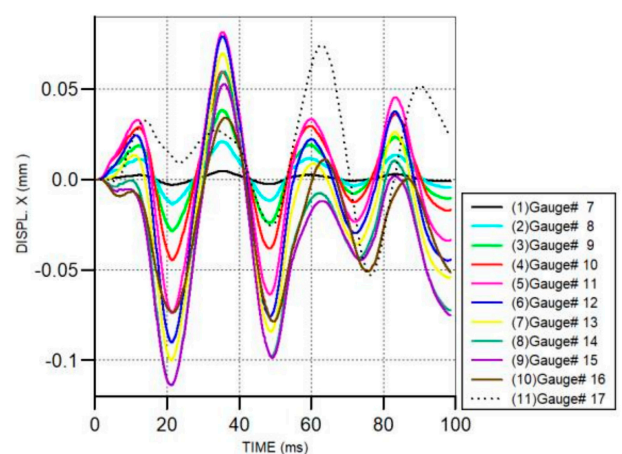

(b) Displacement-X (entire wall No. 1)

Figure 14. Cont. 


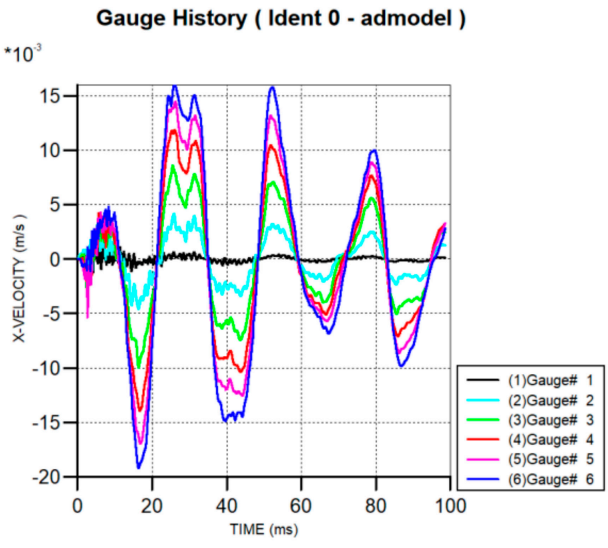

(c) Velocity $-X$ (entire wall No. 4)

Gauge History ( Ident 0 - admodel)

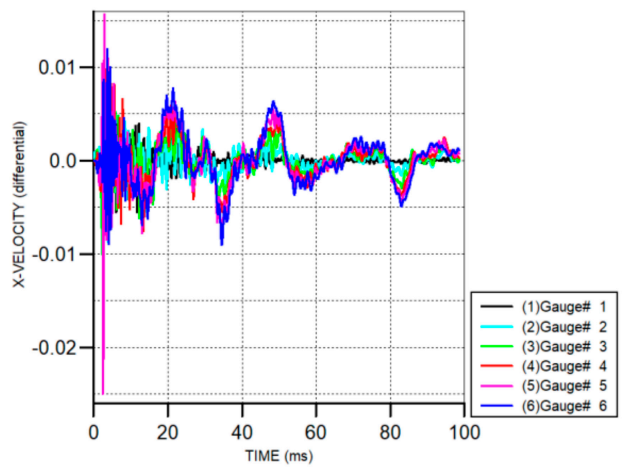

(e) Acceleration-X (entire wall No. 4)

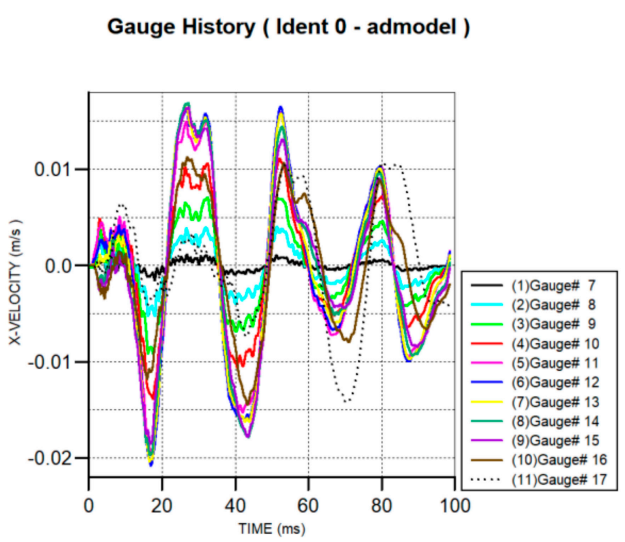

(d) Velocity $-X$ (entire wall No. 1)

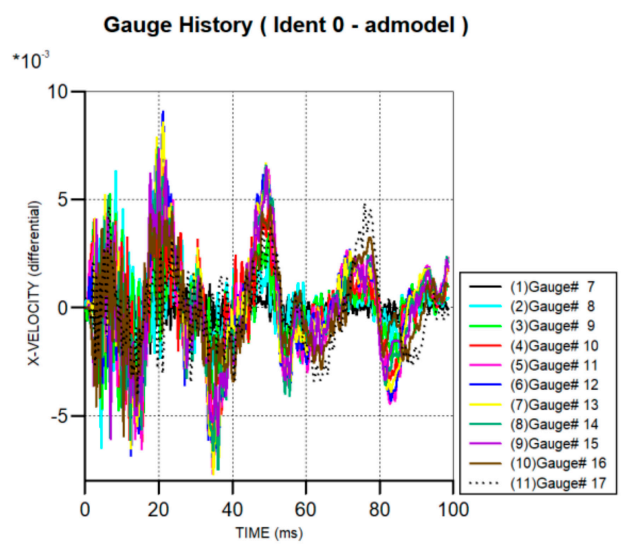

(f) Acceleration $-\mathrm{X}$ (entire wall No. 1)

Figure 14. Displacement, velocity, and acceleration at certain sensors for Case 3.

\section{Conclusions}

This study proposed a method for evaluating the degree of protection of military and civilian protective structures. When constructing protective structures, the facilities must be designed and verified to satisfy the required degree of protection stipulated in the protection design criteria. However, time and economic constraints make it difficult to repeatedly perform actual blast tests whenever verification is required. Furthermore, it is highly effective to use numerical analysis to evaluate the protective performance of facilities that are already installed and operational, without a verification process of their protective performance. However, due to the lack of specified procedures for numerical analysis based on finite element analysis, there are several difficulties in practice.

Accordingly, this study proposed a protective performance evaluation method for the existing $\mathrm{K} 9$ artillery position according to an explosion scenario and compared the results with the protective performance standards stipulated in the protection criteria. Unfortunately, the detailed information about the explosion scenario, explosion weight, and standoff distance are restricted due to military secrets. However, the battle experiments and the FE simulation results show very similar protection performance. In particular, this study proposed a basic procedure for evaluating the protective structures in the future by presenting analysis conditions and blast loading conditions considering dynamic factors pertaining to mission, enemy, terrain and weather, troops and support available, time available, and civil consideration (METT+TC) within the context of the current battle situation.

From this study, the $\mathrm{K} 9$ artillery position in operation has adequate protective performance. Based on this, a basic procedure for evaluating the protective performance of structures using finite element analysis 
in the future was provided. It can be utilized to evaluate the protection level for military facilities against enemy weapons as well as civilian buildings against terrorist explosions.

Author Contributions: Conceptualization, K.K.; Methodology, K.K.; Software, Y.-J.P.; Validation, Y.-J.P. and K.K.; Formal Analysis, K.K.; Investigation, K.K.; Resources, Y.-J.P.; Data Curation, K.K.; Writing-Original Draft Preparation, K.K.; Writing-Review and Editing, K.K.; Visualization, K.K.; Supervision, Y.-J.P.; Project Administration, Y.-J.P.; Funding Acquisition, Y.-J.P. All authors have read and agreed to the published version of the manuscript.

Funding: This research was supported by a grant (20SCIP-B146646-03) from the Korea Agency for Infrastructure Technology Advancement.

Conflicts of Interest: The authors declare no conflict of interest. The funders had no role in the design of the study; in the collection, analyses, or interpretation of data; in the writing of the manuscript, or in the decision to publish the results.

\section{References}

1. R.O.K.; Department of Defense. Design Standards for Military Protective Structures; Department of Defense: Seoul, Korea, 1998.

2. Dusenberry, D.O. Handbook of Blast-Resistant Design of Buildings; John Wiley \& Sons Inc.: Hoboken, NJ, USA, 2010; pp. 3-5.

3. Hadianfard, M.A.; Malekpour, S.; Momeni, M. Reliability analysis of H-section steel columns under blast loading. Struct. Saf. 2018, 75, 45-56. [CrossRef]

4. Ritchie, C.B.; Packer, J.A.; Seica, M.V.; Zhao, X. Behaviour and analysis of concrete-filled rectangular hollow sections subject to blast loading. J. Constr. Steel Res. 2018, 147, 340-359. [CrossRef]

5. Sugiyama, Y.; Wakabayashi, K.; Matsumura, T.; Nakayama, Y. Numerical study of the effect of high-explosive storage facility shape on the azimuthal distribution of blast-wave pressures. Eur. J. Mech. B Fluids 2020, 79, 153-164. [CrossRef]

6. Zhang, B.; Zhao, W.; Wang, W.; Zhang, X. Pressure characteristics and dynamic response of coal mine refugechamber with underground gas explosion. J. Loss Prev. Process Ind. 2014, 30, 37-46. [CrossRef]

7. Kim, D.; Matsumura, T.; Nakayama, Y. Propagation and attenuation characteristics of blast wave pressure generated from an explosion inside an earth-covered magazine. Sci. Tech. Energetic Mater. 2013, 74, 100-105.

8. Kim, W.K.; Mogi, T.; Dobashi, R. Effect of propagation behaviour of expanding spherical flames on the blast wave generated during unconfined gas explosions. Fuel 2014, 128, 396-403. [CrossRef]

9. Sklavounos, S.; Rigas, F. Computer-aided modeling of the protective effect of explosion relief vents in tunnel structures. J. Loss Prev. Process Ind. 2006, 19, 621-629. [CrossRef]

10. Sugiyama, Y.; Tanaka, T.; Matsuo, A.; Homae, T.; Wakabayashi, K.; Matsumura, T.; Nakayama, Y. Numerical simulation of blast wave mitigation achieved by water inside a subsurface magazine model. J. Loss Prev. Process Ind. 2016, 43, 521-528. [CrossRef]

11. Wang, H.; Wu, C.; Zhang, F.; Fang, Q.; Xiang, H.; Li, P.; Li, Z.; Zhou, L.; Zhang, Y.; Li, J. Experimental study of large-sized concrete filled steel tube columns under blast load. J. Constr. Build. Mater. 2017, 134, 131-141. [CrossRef]

12. Zhang, F.; Wu, C.; Zhao, X.-L.; Heidarpour, A.; Li, Z. Experimental and numerical study of blast resistance of square CFDST columns with steel-fibre reinforced concrete. J. Eng. Struct. 2017, 149, 50-63. [CrossRef]

13. Department of the Army. ADP 5-0 The Operation Process. 2019. Available online: https://rdl.train.army. mil/catalog-ws/view/100.ATSC/E4166A5D-0FE7-4780-916A-A7E9B227147C-1337689957702/adp5_0.pdf (accessed on 3 July 2020).

14. Baker, W.E.; Westine, P.S. Methods of Predicting Blast Loads Inside and Blast Fields Outside Suppressive Structures; EM-CR-76026, Report No. 5, Edgewood Arsenal; Aberdeen Proving Ground: San Antonio, TX, USA, 1975.

15. U.S. Department of Defense. Unified Facilities Criteria (UFC) 3-340-02 Structures to Resist the Effects of Accidental Explosion; U.S. Department of Defense: Washington, DC, USA, 2008; pp. 87-90.

16. Krauthammer, T. Modern Protective Structures; CRC Press: Boca Raton, FL, USA, 2008; pp. 65-79.

17. Ngo, T.; Mendis, P.; Gupta, A.; Ramsay, J. Blast loading and blast effects on structures-An overview. Electron. J. Struct. Eng. 2007, 7, 76-91. 
18. Kim, S.B.; Oh, K.D.; Baek, S.H.; Lee, J.H.; Park, Y.J.; Baek, J.H. Protective Structural Engineering; ChungMoonGak Press: Seoul, Korea, 2015; pp. 37-40.

19. Defense Installations Agency, Department Military Facilities Criteria 2-20-10. Design Criteria for Explosion-Proof and Bulletproof Facilities; Department of Defense: Seoul, Korea, 2008; pp. 50-57.

20. Ammann and Whitney. Design of Masonry Structures to Resist the Effects of HE Explosions; Consulting Engineers: New York, NY, USA, 1976.

21. Schumacher, R.N. Air Blast and Structural Response Testing of a Prototype Category III Suppressive Shield, BRL Memorandum Report No. 2701; U.S. Army Ballistic Research Laboratory, Aberdeen Proving Ground: Harford County, MD, USA, 1976.

22. Esparza, E.D. Estimating External Blast Loads from Suppressive Structures; Edgewood Arsenal Contract Report EM-CR-76030, Report No. 3; Edgewood Arsenal, Aberdeen Proving Ground: Harford County, MD, USA, 1975.

23. Stea, W. Nonlinear Analysis of Frame Structures to Blast Overpressures; Contractor Report ARLCD-CR-77008; Ammann and Whitney Consulting Engineers: New York, NY, USA; U.S. Army Armament Research and Development Command: Dover, NJ, USA, 1977.

24. Gregory, F.H. Blast Loading Calculations and Structural Response Analyses of the 1/4-Scale Category I Suppressive Shield; BRL Report No. 2003; U.S. Army, Ballistic Research Lab., Aberdeen Proving Ground: Harford County, MD, USA, 1977.

25. Nelson, K.P. The Economics of Applying Suppressive Shielding to the M483A1 Improved Conventional Munitions Loading, Assembling and Packing Facility; Technical Report No. EM-TR-76087; Edgewood Arsenal, Aberdeen Proving Ground: Harford County, MD, USA, 1977.

26. Stewart, M.G. Reliability-based load factor design model for explosive blast loading. Struct. Saf. 2018, 71, 13-23. [CrossRef]

27. Xu, J.; Wu, C.; Xiang, H.; Su, Y.; Li, Z.X.; Fang, Q.; Hao, H.; Liu, Z.; Zhang, Y.; Li, J. Behaviour of ultra high performance fibre reinforced concrete columns subjected to blast loading. Eng. Struct. 2016, 118, 97-107. [CrossRef]

28. Faber, M.H.; Kübler, O.; Fontana, M. Modeling consequences due to failure of extraordinary structures. In Probabilistic Safety Assessment and Management; Springer: London, UK, 2004; pp. 488-493.

29. Zhang, X.; Bendon, C. Vulnerability and protection of glass windows under blast: Experiments, methods and current trends. Int. J. Struct. Glass Adv. Mater. Res. 2017, 1, 10-23. [CrossRef]

30. Razaqpur, A.G.; Tolba, A.; Contestabile, E. Blast loading response of reinforced concrete panels reinforced with externally bonded GFRP laminates. Compos. Part B Eng. 2007, 38, 535-546. [CrossRef]

31. Gribniak, V.; Misiunaite, I.; Rimkus, A.; Sokolov, A.; Šapalas, A. Deformations of FRP-Concrete Composite Beam: Experiment and Numerical Analysis. Appl. Sci. 2019, 9, 5164. [CrossRef]

32. Tekalur, S.A.; Shukla, A.; Shivakumar, K. Blast resistance of polyurea based layered composite materials. Compos. Struct. 2008, 84, 271-281. [CrossRef]

33. LS-DYNA. User's Manual; Livermore Software Technology Corporation: Worcester, UK, 2009; pp. 12-30.

34. Riedel, W.; Thoma, K.; Hiermaier, S. Numerical Analysis Using a New Macroscopic Concrete Model for Hydrocodes. In Proceedings of the 9th International Symposium on Interaction of the Effects of Munitions with Structures, Berlin, Germany, 3-7 May 1999; pp. 315-322.

35. Kadhom, B. Blast Performance of Reinforced Concrete Columns Protected by FRP Laminates. Ph.D. Thesis, University of Ottawa, Ottawa, ON, Canada, 2016.

36. Hohnson, G.R.; Cook, W.H. A Constitutive Model and Data for Metals Subjected to Large Strains, High Strain Rates and High Temperatures. In Proceedings of the Seventh International Symposium on Ballistics, Hague, The Netherlands, 19-21 April 1983; pp. 541-548.

37. Baker, W.E.; Cox, P.A.; Westine, P.S.; Kulez, J.J.; Strehlow, R.A. Explosion Hazards and Evaluation; Elsevier Scientific Publishing Company: Amsterdam, The Netherlands, 1983.

Publisher's Note: MDPI stays neutral with regard to jurisdictional claims in published maps and institutional affiliations. 